\title{
Economic and Mathematical Modeling of Demand for Recreational Forest Management in Ukraine
}

\author{
Olga Kneysler* \\ Finance Management and Insurance \\ Department \\ Ternopil National Economic University \\ Ternopil, Ukraine \\ olgakne@gmail.com
}

\author{
Inna Zhurba \\ Department of Social Welfare \\ Cherkasy State Technological \\ University \\ Cherkasy, Ukraine \\ dream197708@gmail.com \\ Nataliia Hrechanyk \\ Department of Management and \\ Marketing \\ Vasyl Stefanyk Precarpathian National \\ University \\ Ivano-Frankivsk, Ukraine \\ natali.gre@gmail.com
}

\author{
Nataliia Spasiv \\ Department of Finance \\ Ivano-Frankivsk National Technical \\ University of Oil and Gas \\ Ivano-Frankivsk, Ukraine \\ vladnat@gmail.com
}

\begin{abstract}
The article is devoted to the research of recreational forest management problems Based on the review of scientific works of foreign and domestic scientists, the main aspects of economic and mathematical modeling of the demand for recreational forest use and the main criteria for the attractiveness of recreational forest areas for recreation have been determined. An economic and mathematical model of determining the demand for recreational services, which is based on the study of the behavior and interests of the recreation, is proposed. Taking into account the economic criteria of the demand model, a mathematical model is proposed that realizes the search for the optimal recreation strategy based on the criterion of financial constraints and maximization of total usefulness. The results of the proposed models testing on one of the average forestry showed that the strategic behavior of the recreant, taking into account the economic criterion, is to minimize the total cost of the recreational process. The modeling results show that this recreational facility is in demand. The model can be adapted to other conditions of recreational areas functioning.
\end{abstract}

\section{Keywords-recreation, forestry, demand, model, cost}

\section{INTRODUCTION}

Recreation is one of the many functions of forest use. Ukraine forests cover about $15 \%$ of the country surface and the Ukraine Forest Code ensures the general right to freely enjoy its recreation function. Given the transformational changes that occur in both foreign and national economies, the issue of efficient use of the territories resource base without causing environmental damage to the environment becomes increasingly relevant, so in these conditions the priority is given to the optimal recreational forest use. Recreational forestry in Ukraine remains a free service. In last decades, amenities aiming at attracting people have been installed and the development of forest leisure infrastructure continues. Due to its public good characteristics and the absence of related markets, forest recreation is a non-market service and its demand is hence not directly observable.

\section{BACKGROUND}

Economic and mathematical modeling of recreational forest management system elements was done by both foreign and domestic scientists and practitioners.

Among scientists-foreigners who dealt with the problems of economic and mathematical modeling of demand for recreational forest use can be noted next works: Nicolas Borzykowski, Andrea Baranzini and David Maradan [1], Anna Bartczak, Jeffrey Englin and Arwin Pang [2], Arne Arnberger1, Martin Ebenberger, Ingrid E. Schneider, Stuart Cottrell, Alexander C. Schlueter, Eick von Ruschkowski, Robert C. Venette, Stephanie A. Snyder and Paul H. Gobster [3], Paula Simo es, Eduardo Barata and Luis Cruz [4], Léa Tardieu and Laëtitia Tuffery [5], Mariusz Ciesielski and Krzysztof Stereńczak [6] and others.

Nicolas Borzykowski, Andrea Baranzini and David Maradan in the paper [1] researchs the demand for recreation in Swiss forests using the personal travel cost method. They use a two-steps method, a hurdle zerotruncated negative binomial model, that allows accounting for a large number of non-visitors caused by the off-site phone $\mathrm{s}$ inspect and over-dispersion. Given the national scale of the inspect, they group forest areas to evaluates consumer excess and travel expense elasticities for relatively uniform forest types. They find that forest recreation actions are travel expense inelastic and show that recreation in Swiss forests gives numerous benefits to the population. The most populous zone is associable with greater consumer excess, but the 1 shortage of recreational infrastructure may reason a lower recreational benefit in some areas. For these areas, recreational benefits may be lower than cost caused by support. More efficient administration would require either refining recreational infrastructure thus increasing benefits, or exchanging the forest status from recreational to biodiversity forest therefore decreasing management expense [1].

In the paper [2] Anna Bartczak, Jeffrey Englin and Arwin Pang identificated that while the demand for forest 
recreation has been a main covered in many paper, little attention has been used so far to seasonal demand. In a forest recreation context, the periodical analysis is especially interesting because of inter-temporal switch in forest attributes throughout the year which can affect trip-taking behavior. In this article, the simulation model of seasonal forest visitation is well-grown to produce a richer reasonable of the role played by periodic fluctuation on a division of forest social advantages. The researches is based on an onsite inspect conducted in four forests in Poland. Results demonstration that the most useful forest trips are those taken in autumn and that seasonal trips are divided [2].

Arne Arnberger1, Martin Ebenberger, Ingrid E. Schneider, Stuart Cottrell, Alexander C. Schlueter, Eick von Ruschkowski, Robert C. Venette, Stephanie A. Snyder and Paul H. Gobster in their paper "Visitor Preferences for Visual Changes in Bark Beetle-Impacted Forest Recreation Settings in the United States and Germany" [3] examines visitor response to visual changes inconifer forest recreation settings resulting from forest insect infestations, how visitors choose trade-offs between physical and social forest environment effects, or how visitor precedence might vary by nation. Their research explored forest visitor precedence with a discontinuous choice experiment that imaginly modelling conifer forest with different levels of bark beetle outbreaks, forest and visitor management practices, and visitor use levels and configuration. On-site surveys were conducted with visitors to State Forest State Park in Colorado, Lake Bemidji State Park in Minnesota, and Harz National Park in Germany. Results showed that the situation of the instantaneous forest surrounding was the most significant variable influencing users' landscape preferences. Users preferred healthy reach forest stands and disliked forests with substantial dead wood. Some users was the most important social factor influencing visitor landscape preferences. Differences in the influence of physical and social impacts on visual choices existed between study sites. Findings give advice to that both visual forest circumstances and consumers use administration are main concerns in addressing outlook preferences for beetleimpacted forest recreation zones [3].

Paula Simo es, Eduardo Barata and Luis Cruz in their paper [4] research the problem to raise the demand for public forests for recreation and o promotes an in-depth data research supported by the supplementary use of count data and ordered simulation models. From a policy-making prospect, while count data simulation models enable the estimation of monetary prosperity measures, ordered simulation models allow for the broad use of the database and produce a more flexible research of data. The main purpose of this paper is to research the individual forest recreation demand and to get a measure of its present use value. To permits a more complete research of the forest recreation demand formation the econometric method supplements the use of count data simulation models with ordered category simulation models using data received by means of an on-site survey in the Bussaco National Forest. Generally, both simulation models show that travel expenses and substitute prices are main explanatory variables, visits are a normal good and demographic variables seem to have no influence on demand. Notably, estimated cost and income elasticities of demand are enough low. Accordingly, it is possible to evidence that travel price in excommunication may be calculated to have a low influence on visitation levels [4].

LéaTardieu and LaëtitiaTuffery in their paper "From supply to demand factors: What are the determinants of attractiveness for outdoor recreation?" [5] developed a novel method to predict, in spatially explicit terms, the recreation attractiveness potential combining supply and demand factors. This method is based on the combination and transfer of a Lancasterian function of biophysical aspects and a travel cost model based on agents' sociodemographic characteristics. They further validate the usefulness of the proposed recreation model by using it in the evaluation of a regional park charter pursuing two main objectives: recreational attractiveness and habitat quality (modeled with InVEST). The results demonstrate first that the biophysical context plays a large role in the recreational trip choice and thus should not be ignored in travel cost studies. Second, from a policy guidance perspective, we show that providing spatial information appears particularly critical for ES to be a useful lever for action in day-to-day decision-making [5]. Mariusz Ciesielski and Krzysztof Stereńczak [6] have been analyzed. 109 papers published in the years 2000-2016 In the work, five main issues were discussed, which constitute the study subject i.e.: a) the preferred forest type and function; b) expenses incurred by people to reach a forest (time and distance); c) the society's demand for technical infrastructure and forest management; d) factors disturbing the recreation in forest areas; e) reasons and frequency of visits to forests for recreation purposes [6]. The results indicate that the following have an impact on the perception of forests: tree stand factors (age, species composition, etc.), social factors (age, material status, interests, etc.), and factors related to human activity (the extent of forest operations, noise, littering, etc.). Based on the literature, it is possible to indicate a model forest, which in view of respondents, is described as the one that is preferred for recreation purposes. The model differs depending on the analyzed part of Europe [6].

Among the scientific achievements of Ukrainian scientists and practitioners who have researched the problems of recreational forest management there are no works dedicated to determining the demand for recreational forest management services. This state of affairs is caused by the fact that in Ukraine, as it was started above, recreational forest use is free and accordingly acts as a free public good. However, due to the circumstances of the decentralization reform, the forefront is given to the priority use of the territories resource potential, and as recreational forestry has already started, especially in the western region of Ukraine, it becomes an urgent issue and an important reserve of attracting foreign tourists and recreational services consumers, which will eventually lead to demand for related services and create good financial potential for the development of recreational areas. In spite of the lack of research works, which specifically relate to the study of demand for reforestation forest use in the Ukrainian scientific environment, there are worthy problematic works of such national scientists as I.F. Kalutsky [7], O. R. Pelyukh [8], Myklush [9], M. M. utya [10] and others.

In particular, it should be noted that domestic scientists contribute to solve the problems of recreational forest 
management by forming a system of forest areas recreational assessment using selective methods, allow to obtain annually the necessary data on the allocation of area according to the relevant indicators, which will allow operational decision making maintaining forestry facilities and increasing the use of the recreational potential of these forests [10]. The paper proposes the use of a hierarchy analysis method to make optimal decisions in the field of recreational forest management based on multicriteria selection. A specific example is an algorithm for using this method to evaluate the attractiveness of forest plantations for their use in recreation. I.F. Kalutskyi in his work [7] identifies the main measures to improve the attractiveness of recreational forestry in the Carpathian region, among which to improve the aesthetic and recreational properties of forests, improving the trail system and others Noteworthy is the work [8] of the Ukrainian scientist O.R. Pelyukh, who researched the preference of recreant on the characteristics of recreational forests by applying one of the expressed advantages investigation methods - a method of experiment with a choice, the theoretical basis of which is the probabilistic theory of the usefulness maximization of $\mathrm{D}$. Makfadden and "Characteristic" theory of consumer behavior, formulated by K. Lancaster.

The simulation of discrete recreation of recreational characteristics of the forest for recreation was performed using multivariate regression models - logos and probit models - by the highest likelihood method using BIOGEME 1.8 software. The results of the analysis of the data revealed that the population of Lviv region. Prefers mixed-age forests with recreational areas with information and educational stands. The regression coefficients estimates for these characteristics are statistically significant, positive, and highest in both models. At the same time, respondents are not inclined to visit a forest located far from their place of residence and a forest with dead wood. The maximum willingness to pay and the willingness to overcome the distance to visit the forest, which corresponds to the preferences of the respondents, are determined. The necessity to integrate the results of the study into the practice of managerial decision making to reduce raw materials and expand recreational use of forests, thus forming recreationally attractive forest landscapes and resistant to climate change and anthropogenic loads of stands is substantiated. Yatsenko A. D. in his scientific research [9] considers the main natural factors that contribute to the development of tourism and recreation, namely the influence of forest plantations on the state of the atmosphere, the reduction of wind speed, the creation of a special microclimate in the forest and the release of volatiles.

Thus, having summarized the scientific achievements related to the problems of recreational forest use, we can conclude that in Ukraine previous studies of the factors influencing demand formation have already been carried out, by forming the attractiveness of recreational territories as mentioned above, and the application of international practices of economic and mathematical modeling of the demand and economic interests of recreation will be appropriate to form an economic and mathematical model to be tested in the Carpathian region.

\section{III.MATERIALS AND METHODS}

Recreational resources make up the most important part of the natural potential of the territorial-recreational system (TRS), the main function of which is to maximally meet the needs of recreational tourists; improvement; entertainment; physical, cultural and aesthetic development. Therefore, recreant is the dominant object of TRS, which, while meeting its needs, places the main emphasis on economic interests.

In modern conditions, economic and mathematical methods have become an important tool for obtaining a deeper and more complete knowledge of the quantitative and qualitative aspects of the certain processes and phenomena economic mechanism. Therefore, economic and mathematical modeling is one of the most promising areas of economic research, which allow not only to evaluate the process from the qualitative side, but to provide a reasonable quantitative assessment of the functioning of economic systems and the processes in them. [12]. In forest management, economic modeling becomes especially relevant as it enables the recreationist realistically evaluate their financial resources to be used for recreation.

We are modernizing the classic model of the demand for recreation [13], choosing as a basis a territorial and recreational system that is territorially owned by forestry. Let the TRS include $\mathrm{m}$ points of recreation (TRO). We denote by $\mathrm{J}$ the set of services provided by the TRS as a whole, and by $J_{i}=(i=\overline{1, m})$ - many services provided in TRO and $(i=\overline{1, m})$, evidently, $J_{i} \subset J, i=\overline{1, m}$. Assuming that a potential recreational person intends to participate in the recreational process of a given TRS, then the behavior of the recreant from the standpoint of his interests should be studied. To build a model, we present its components:

- $s_{i}$ - the average expected cost of moving a recreant from the location of $M$ to the point of recreation and $(i=\overline{1, m})$;

- $d_{i \prime}$, - the average expected cost of moving a recreant between recreational items $i^{\prime}$ and $i$ (it can be assumed that $\left.d_{i i}=0, \quad i=\overline{1, m} ; d_{i^{\prime}}=d_{i i}, \quad i=\overline{1, m}, i^{\prime} \neq i\right)$;

$-c_{i j i}-$ the average expected cost of the service $j_{i} \in J_{i}$ at point $i$;

$-P_{i}-$ the average expected cost of moving the recreant from point to point $M$ after the completion of the recreational process (often $P_{i}$ and $s_{i}$ may coincide);

$$
\begin{aligned}
-_{i} & =\left\{\begin{array}{l}
1, \text { if the recreant moves from point } M \text { to po int } i \text { before } \\
\text { the recreational process begins; } \\
0 \text { otherwise; }
\end{array}\right. \\
-v_{i} & =\left\{\begin{array}{l}
1, \text { if the recreant moves from point } M \text { to point } i \text { after } \\
\text { the recreational process is completed } ; \\
0 \text { otherwise; }
\end{array}\right. \\
-x_{i_{j_{i}}} & \left\{\begin{array}{l}
1, \text { if the recreant uses servise at point } i j_{i} \in J_{i} ; \\
0 \text { otherwise; }
\end{array}\right.
\end{aligned}
$$




$$
-z_{i^{\prime} i}=\left\{\begin{array}{l}
1, \text { if the recreant moves from point } i^{\prime} \text { to point } i \text { meet } \\
\text { specific needs } \\
0 \text { otherwise }
\end{array}\right.
$$

Typically, the recreant needs a set of $N \subset J$ the number of $\mathrm{n}$ services that are in a given TRS (that is, in the set $J$ ), but there is no complete set of services $\mathrm{N}$ in each individual TRO with number $i(i=\overline{1, m})$. This situation is quite realistic and does not need separate justifications. In this case, the recreant is forced to use some subset of the recreation points that are a true TRS.

Considering the economic criterion, the strategic behavior of the recreant is to minimize the total cost of the recreational process and the cost of moving it from point $M$ to TRS and back from TRS to point $M$. Given the notation above, this (average) value can be expressed as follows:

$$
F=\sum_{i=1}^{m} \sum_{j_{i} \in J_{i}} c_{i j_{i}} x_{i j_{i}}+\sum_{i=1}^{m} p_{i} v_{i}+\sum_{i^{\prime}=1}^{m} \sum_{i=1}^{m} d_{i^{\prime} i} z_{i^{\prime} i}
$$

The mathematical model that realizes the search for the optimal recreation strategy is:

$$
\begin{aligned}
& \min F \\
& \sum_{i=1}^{m} y_{i} \leq 1, \\
& \sum_{i=1}^{m} v_{i} \leq 1, \\
& \sum_{i=1}^{m} \sum_{j_{i} \in J_{i}} x_{i j} \leq n, \\
& y_{j}=0,1 ; v_{i}=0,1 ; i=\overline{1, m}, \\
& x_{i_{i}}=0,1 ; j_{i} \in J ; i=\overline{1, m,} \\
& z_{i^{\prime} j}=0,1 ; i^{\prime}, i=\overline{1, m ;} i^{\prime} \neq i .
\end{aligned}
$$

Conditions (2) - (8) are logical programming. The restriction (3) indicates that the recreant moves from the point $M$ to one of the recreation points.

Similarly (4) is a restriction: the recreant returns to point $\mathrm{M}$ from one of the recreation points.

The content of restriction (5) is that for a recreant each service $j \in N$ is satisfied at only one of the recreation points.

Restriction (6) - (8) is a restriction on the discreteness of the desired variables. Note also that restrictions (3) - (5) can be replaced by equality constraints.

It is also important for an individual recreant to optimally allocate financial resources to services that can be provided to the recreant at a given point of recreation (ie TRO). Under these conditions, we introduce the following notation:

$-s-$ the maximum amount of financial resources that a recreant can allocate to satisfy the services of the recreational process;

$-n-$ number of services at this recreation center;

$-c_{i}-$ the cost of one i-type service $(i=\overline{1, n})$; $-x_{i}-$ required number of services of the $i$ type used by the recreant;

$-k_{i}$ - the usefulness of one and the same service (this may be some weighting that evaluates the significance of the one or other service or, more generally, the definition of some recreational utility function).

Then the reasonable behavior of the recreant will be to maximize the total usefulness of their recreational process, given the financial constraints. A model of this behavior will look like:

$$
\begin{aligned}
& \max \sum_{i=1}^{n} k_{i} x_{i}, \\
& \sum_{i=1}^{n} c_{i} x_{i} \leq s, \\
& x_{i} \geq 0, i=\overline{1, n .} \\
& x_{i} \in Z, i=\overline{1, n .}
\end{aligned}
$$

Taking into account that under given conditions the recreant will get optimal satisfaction at the minimum expenses using recreational services, it will indicate that this recreation object is in demand. The recreational demand model will be presented using the classical approach; let:

$-K_{i j}$ - the number of recreational $\mathrm{j}$-th TRS who arrived from the i-th point of demand for recreation; TRS;

$-n_{j}$ - capacity (maximum possible capacity) of the $j$-th

$-m_{j}-$ population of $\mathrm{j}$-th point of demand;

$-r_{i j}-$ the distance between the i-th point of demand and the j-th TRS.

Then:

$$
K_{i j}=k \frac{m_{i}^{m} n_{j}^{n}}{r_{i j}^{r}}
$$

This model is effective for the distance between the point of departure and the point of recreation approximately from $160 \mathrm{~km}$ to 240 , and for longer distances the model is modified as it must take into account the factor of psychological inertia of the recreants.

\section{RESUlTS}

To approve the model we choose the forestry, which is the most forested in the Carpathian region. Such forestry is SE "Vygoda Forestry", wich has five village councils and one integrated territorial communities (ITC), to which certain forests are concerned, including: Shevchenkivsk village council ( 6 forestries); Obolonsk village council (1 forestry); Pidliskivsk Village Council (1 forestry); Lolynsk village council (1 forestry); Maloturyansk village council (1 forestry); Vygoda ITC (there are 7 former village and village councils within the ITC) (8 forestries). Depending on their basic functions, forests are divided into the following categories: forests of nature conservation, scientific, historical and cultural purpose; recreational and recreation forests; protective forests; operating forests. Landscape taxation has been carried out in the recreation and recreation 
forests of SE "Vygoda Forestry" (sub-categories of protection "Forests within settlements", "Forest park part of forests of green zones", "Recreational and health forests outside the green zones"). Based on the natural features of the area and the purpose of the forests, functional zoning of the territory was carried out, as a result of which a zone of mass rest, an area of intensive recreation and an area of extensive recreation were allocated. The dominant type of landscape in recreational forests is indoor, which occupies $63.59 \%$ of the area, the share of semi-open and open landscapes is $21.64 \%$ and $5.58 \%$ respectively (Table 1 ).

TABLE I. DISTRIBUTION OF FOREST AREA FOR RECREATIONAL PURPOSE OF SE "VYGODA FORESTRY" BY LANDSCAPE TYPES

\begin{tabular}{|c|c|c|c|c|c|c|c|c|c|c|}
\hline \multirow{3}{*}{$\begin{array}{c}\text { Total, } \\
\%\end{array}$} & \multicolumn{10}{|c|}{ Including the types of landscape } \\
\hline & \multicolumn{3}{|c|}{ closed } & \multicolumn{3}{|c|}{ semi-open } & \multicolumn{4}{|c|}{ opened } \\
\hline & $1 A$ & $1 B$ & total & $2 A$ & $2 B$ & total & $3 A$ & $3 B$ & $3 C$ & total \\
\hline \multicolumn{11}{|c|}{ Mass rest area } \\
\hline 47.81 & 36.6 & 0.8 & 37.5 & 3.9 & 2.8 & 6.7 & 0.0 & 2.5 & 1.1 & 3.6 \\
\hline \multicolumn{11}{|c|}{ Area of intensive recreation } \\
\hline 12.95 & 7.7 & 0.0 & 7.7 & 2.0 & 2.1 & 4.7 & 0.0 & 0.1 & 0.5 & 0.5 \\
\hline \multicolumn{11}{|c|}{ Area of extensive recreation } \\
\hline 29.60 & 18.4 & 0.00 & 18.4 & 2.3 & 7.9 & 10.2 & 0.5 & 0.1 & 0.4 & 1.0 \\
\hline \multicolumn{11}{|c|}{ Other areas of recreational forests } \\
\hline 0.45 & 0.0 & 0.0 & 0.0 & 0.0 & 0.0 & 0.0 & 0.0 & 0.0 & 0.5 & 0.5 \\
\hline \multicolumn{11}{|c|}{ Total: } \\
\hline 90.8 & 62.8 & 0.8 & 63.6 & 8.8 & 12.8 & 21.6 & 0.5 & 2.6 & 2.4 & 5.6 \\
\hline \multicolumn{11}{|c|}{ In addition, land on which the type of landscape is not determined } \\
\hline 9.19 & 0.0 & 0.0 & 0.0 & 0.0 & 0.0 & 0.00 & 0.0 & 0.0 & 0.0 & 0.0 \\
\hline
\end{tabular}

According to optimal standards, the ratio of types of landscapes should be $70-80 \%, 15-20 \%$ and $5-10 \%$. As can be seen from the table. 1, the actual landscape structure is close to optimal. To achieve the optimum ratio of landscapes it is necessary to carry out felling of the formation of landscapes, as well as planting ornamental crops. The area of recreational purpose forests of SE "Vygoda Forestry" covers $11(\mathrm{~m})$ territorial and recreational sites. The capacity of a single recreational workload at a single recreation facility ranges from 10 to 50 people. In general, an enterprise's TRS covers $35(J)$ services, and the number of services provided in one TRO ranges from 2 to 5 (Ji). Since the approbation of model (1) requires the study of the behavior of the recreant, then from the standpoint of his interests we will match the components for the construction of the model on the example of one TRO:

$$
F_{1}=\sum_{i=1}^{11} \cdot \sum_{5 \in 5} 0 \cdot 1+\sum_{i=1}^{11} 229 \cdot 1+\sum_{i^{\prime}=1}^{11} \cdot \sum_{i=1}^{11} 79 \cdot 1 ; \quad F_{1}=308
$$

It was accepted that $s_{i}=150 \mathrm{UAH}$ (from Ivano-Frankivsk location to Recreation Point Vygoda) (distance from the location to the recreation point is approximately $70 \mathrm{~km}$; the cost takes into account the movement by road, and based on the current fuel prices it will be $150 \mathrm{UAH} / 70 \mathrm{~km}$.); $d_{i^{\prime}}=79 U A H$. (let the tourist move between the recreation points from Vygoda to Vyshkiv, owned by the same SE "Vygoda Forestry"; the distance between them is $37 \mathrm{~km}$; taking into account the current fuel prices will be 79 $\mathrm{UAH} / 37 \mathrm{~km}$.); $c_{i j i}=0$ (since the recreational facilities in the recreational forests are used free of charge, the average cost of the service $j_{i} \in J_{i}$ at the point $i$ is zero).

However, the strategic behavior of the recreant, taking into account the economic criterion, is minimized by the total cost of the recreational process. Therefore, a mathematical model that realizes the search for the optimal recreation strategy has the form:

$$
\begin{aligned}
& \min F \\
& \sum_{i=1}^{11} 0 \leq 1, \\
& \sum_{i=1}^{11} 1 \leq 1, \\
& \sum_{i=1}^{11} \sum_{5 \in 5} 1 \leq 5, \\
& y_{j}=0 ; v_{i}=1 ; i=\overline{1} \\
& x_{i j_{i}}=1 ; 5 \in 35 ; i=\overline{1} \\
& z_{i^{\prime} j}=1 ; 2,1=\overline{1,2 ;} 2 \neq 1 .
\end{aligned}
$$

The calculations indicate that the strategic behavior of the recreant at min will be: $F=229 U A H$. However, with optimal allocation of financial resources during recreation, the model will look like this:

$$
\begin{aligned}
& \max \sum_{i=1}^{5} 9 \cdot 5 \\
& \sum_{i=1}^{5} 0 \cdot 5 \leq 308, \\
& 5 \geq 0, i=\overline{1,2 .} \\
& 5 \in 1, i=\overline{1,2} .
\end{aligned}
$$

Therefore, $\mathrm{F}_{1}=353 \mathrm{UAH}$, which will allow to direct the behavior of the recreant in such a way that in the given financial constraints to maximize the total usefulness of the recreational process. Given that under the given conditions, the recreant receives optimal satisfaction at the lowest cost, it means that this recreation object is in demand. The recreational demand on the example of one TRO model will look like this:

$$
K_{1 \cdot 35}=9 \cdot \frac{11_{1}^{11} \cdot 50_{35}^{50}}{37_{1 \cdot 35}^{37}} ; K=134 .
$$

This model has shown that it is possible to increase the demand for recreation to 134 recreants, while it is effective, since the recreation point is at a distance of $107 \mathrm{~km}$.

On the same principle, we calculate for the other 10 TRO, the results of which are presented in Table 2. The values obtained in Table 2 reveal the interdependence between the content in one TRO and the maximum reception of services at the point of recreation. In particular, the greater the TRO's availability with maximum service delivery, the more useful the recreation is. This indicates that, given financial constraints, a recreant is able to maximize the total usefulness of his or her recreational process. Thus, the $\mathrm{TRO}_{3}$ model of demand for recreation allowed to increase the number of recreation by 258 people, by $\mathrm{TRO}_{7}$ - by 105 recreation, as well as $\mathrm{TRO}_{11}$ - by 95 recreation. 
TABLE II. DEMAND FOR RECREATION MODEL FOR THE 11TH TRO OF SE "VYGODA FORESTRY"

\begin{tabular}{|c|c|c|c|c|c|c|}
\hline \multirow{2}{*}{$\begin{array}{c}\text { TRO } \\
\boldsymbol{i}\end{array}$} & \multicolumn{7}{|c|}{ Indexes } \\
\cline { 2 - 7 } & $\boldsymbol{k}$ & $\boldsymbol{m}$ & $\boldsymbol{n}$ & $\boldsymbol{r}$ & $\boldsymbol{K}$ & $\Delta \boldsymbol{K},+$ \\
\hline 1 & 9 & 11 & 50 & 37 & 134 & 84 \\
\hline 2 & 7 & 10 & 20 & 30 & 47 & 27 \\
\hline 3 & 11 & 14 & 50 & 25 & 308 & 258 \\
\hline 4 & 6 & 9 & 20 & 40 & 27 & 7 \\
\hline 5 & 5 & 8 & 30 & 18 & 67 & 37 \\
\hline 6 & 9 & 13 & 20 & 23 & 102 & 82 \\
\hline 7 & 6 & 9 & 30 & 12 & 135 & 105 \\
\hline 8 & 8 & 9 & 30 & 38 & 56 & 26 \\
\hline 9 & 7 & 11 & 20 & 44 & 35 & 15 \\
\hline 10 & 8 & 5 & 10 & 25 & 16 & 6 \\
\hline 11 & 12 & 14 & 20 & 29 & 115 & 95 \\
\hline
\end{tabular}

These three TRO have the highest maximization as the recreant receives maximum utility. At all other points of recreation we also see an increase in the amount of demand, which is caused by the expansion of services in the objects of recreation. Maximum increase in demand is possible by maximizing the provision of services, which will not allow the tourist to move to other points of recreation. Therefore, this model allows to direct the behavior of recreation of SE "Vygoda Forestry" in such a way that in the given financial constraints maximize the overall usefulness of the recreational process. Under these conditions, the recreant receives optimal satisfaction at the lowest cost, which means that this recreation facility is in demand.

\section{CONCLUSIONS AND RECOMMENDATIONS}

Recreational forestry performs many functions, including the provision of human spiritual needs, increasing labor productivity, integrated use of forest resources, increasing responsibility for the ecological status. However, it is not valued in terms of value, since recreational facilities are provided free of charge. Therefore, forest recreation is a non-market service and therefore its demand is not directly observed. Therefore, the article deals with economic and mathematical modeling of the demand for recreational forest use. Nowadays, economic and mathematical methods in forestry make it possible not only to evaluate the process from the qualitative side, but also to provide a reasonable quantitative assessment. Studies in the countries of Eastern and Western Europe (Bulgaria, Romania, Czech Republic, Slovakia, Germany, Sweden, Switzerland, England) found in experimental catchments that forestry has the potential to influence the quantity and quality of water from catchments, to improve the conditions of groundwater formation, significantly reduce erosion processes in forest management. Multipurpose use of forests is one of the basic requirements of the forest management system, and climate control, water protection, sanitation and aesthetic functions of forests should be given priority. [14].

Therefore, the model was tested on the example of forestry, in particular, SE "Vygoda Forestry", whose area of recreational forests covers 11 territorial and recreational sites, and the territorial and recreational system covers in total 35 services. Its results indicate that the strategic behavior of the recreant, taking into account the economic criterion, is minimized by the total cost of the recreational process. This indicates that the recreant will be satisfied with the recreation by visiting only one object. At the same time, with the optimal allocation of financial resources during recreation, the model changes, and its result indicates that it is possible to direct the behavior of the recreant in such a way that to maximize the total usefulness of the recreational process under given financial constraints. Therefore, the result of economic and mathematical of demand modeling for recreational forest management indicates that under increased conditions, the recreant receives optimal satisfaction at minimal cost, which indicates that the recreational object is in demand. In the future, this model can be tested at other objects of recreation, but it will be effective provided that the distance between the point of departure and the point of recreation is approximately from $160 \mathrm{~km}$ to 240 , and for longer distances the model will be modified, since it must take into account the psychological factor inertia of recreants.

\section{REFERENCES}

[1] Nicolas Borzykowski, Andrea Baranzini and David Maradan, "A travel cost assessment of the demand for recreation in Swiss forests" Agricultural, Food and Environmental Studies, vol. 98, Issue 3, December 2017, pp 149-171.

[2] Anna Bartczak, Jeffrey Englin and Arwin Pang, "When are Forest Visits Valued the Most? An Analysis of the Seasonal Demand for Forest Recreation in Poland", Environmental and Resource Economics, vol. 52, Issue 2, June 2012, pp 249-264.

[3] Arne Arnberger1, Martin Ebenberger, Ingrid E. Schneider, Stuart Cottrell, Alexander C. Schlueter, Eick von Ruschkowski, Robert C. Venette, Stephanie A. Snyder and Paul H. Gobster, "Visitor Preferences for Visual Changes in Bark Beetle-Impacted Forest Recreation Settings in the United States and Germany", Environmental Management, vol. 61, December 2018, pp 209-223.

[4] Paula Simo es, Eduardo Barata and Luis Cruz, "Using Count Data and Ordered Models in National Forest Recreation Demand Analysis", Environmental Management, vol. 52, July 2013, pp. 12491261.

[5] LéaTardieu and LaëtitiaTuffery, "From supply to demand factors: What are the determinants of attractiveness for outdoor recreation?", Ecological Economics, vol. 161, July 2019, pp. 163-175.

[6] MariuszCiesielski and KrzysztofStereńczak, "What do we expect from forests? The European view of public demands", Journal of Environmental Management, Vol. 209, March 2018, pp. 139-151.

[7] I. F. Kalutskyand and M. M. Zapotochnyy "Recreational and sanatory functions of forests in IvanoFrankivsk,problems of expansion and its influence on the tourism development", Karpatskyi kray, vol. 1, 2012, pp.72-78. [in Ukrainian].

[8] O. R. Pelyukh and L. D. Zahvoyska (2018). "Investigation of Lviv region population's preferences regarding recreational forests using choice experiment method", Scientific Bulletin of UNFU, vol. 28(9), 2018, pp. 73-80. [in Ukrainian].

[9] A. D. Yatsenko, "Native resources and resources found in the recreational forestry systems of the Northwest Azov Region", Geography and tourism, vol. 27, pp. 105-112, 2014. [in Ukrainian].

[10] M. M. Kutia, "Determination of indicators of recreational assessment of forest areas by sampling methods", Lisivnytstvo ta dekoratyvne sadivnytstvo, Vol. 171(2), pp. 239-244, 2012. [in Ukrainian].

[11] M. M. Kutia and V. A. Svynchuk, "Using the analytic hierarchy process optimization in practice recreational forest", Lisivnytstvo ta dekoratyvne sadivnytstvo, Vol. 198(2), pp. 38-44, 2014. [in Ukrainian].

[12] O. Konovalov and A. O. Drozd, " The role of economic and mathematical modeling in studies of economic systems" Modeling and forecasting of economic processes [Text]: Proceedings of the XIIth Scientific and Practical Conference. 2018. [in Ukrainian].

[13] I. M. Shkola Tourism Industry Management: A Handbook, Chernivtsi: CHTEI KNTEU, 2003. [in Ukrainian].

[14] L. T. Horal, O. I. Holubchak, I. H. Fadieieva and S.V. Korol Financial decentralization as a means of sustainable regional development: a monograph, Ivano-Frankivsk: IFNTUNG, 2018. 272. [in Ukrainian]. 